\title{
LC-ESI-MS profile, antioxidant activity and cytotoxic screening of Oligomeris linifolia (Vahl) Macbr. (Resedaceae)
}

\author{
Ali M. El-Hagrassy ${ }^{1}$, Ahmed Elkhateeb $^{1 *}$, Sameh R. Hussein ${ }^{1}$, El-Sayed S. Abdel-Hameed ${ }^{2,3}$, Mona M. Marzouk ${ }^{1}$ \\ ${ }^{1}$ Department of Phytochemistry and Plant Systematics, National Research Centre, 33 El Bohouth St., Dokki, Giza, Egypt. \\ ${ }^{2}$ Laboratory of Medicinal Chemistry, Theodor Bilharz Institute, Giza, Egypt. \\ ${ }^{3}$ Chemistry Department, Faculty of Science, Taif University, Saudi Arabia.
}

\begin{tabular}{l}
\hline ARTICLE INFO \\
\hline Article history: \\
Received on: 09/05/2017 \\
Accepted on: 06/06/2017 \\
Available online: 30/08/2017 \\
\hline Key words: \\
Oligomeris linifolia, \\
phenolics, flavonoids, LC- \\
ESI-MS, Antioxidant, \\
Cytotoxicity \\
\hline
\end{tabular}

\begin{abstract}
LC-ESI-MS analysis was investigated for the n-butanol, methanol and water fractions of Oligomeris linifolia, which leads to the identification of twenty-one compounds, among them sixteen compounds were firstly reported from this plant and five compounds were identified previously. Butanol and methanol fractions showed higher antioxidant activity with $\mathrm{IC}_{50}$ values of $10.37 \mu \mathrm{g} / \mathrm{ml}$ and $31.07 \mu \mathrm{g} / \mathrm{ml}$, respectively, compared with that of the standard; Trolox $(33.55 \mu \mathrm{g} / \mathrm{ml})$ using DPPH method. However, water fraction showed lower activity $\left(\mathrm{IC}_{50}\right.$ : $91.86 \mu \mathrm{g} / \mathrm{ml}$ ). The three fractions were also screened for their cytotoxicity and showed weak effect against HCT116, A549 and MCF7 at $100 \mathrm{mg} / \mathrm{ml}$ and no effect against HEPG2.
\end{abstract}

\section{INTRODUCTION}

Resedaceae family contains about 52 species of six genera divided into three tribes, according to the position of ovary, number of carpels and the placentation types (MartínBravo et al., 2007). Astrocarpeae; with the genus Sesamoides, is characterized by apocarpous ovary and marginal placentation, Cayluseae; with the genus Caylusea, showing semiapocarpous ovary and basal placentation, while the remaining 4 genera were included within Resedeae (syncarpic ovary and parietal placentation) (Martín-Bravo et al., 2007). On the basis of the position of calyx, corolla and stamens, the genera of tribe Resedeae were distributed into two sub tribes (Martín-Bravo et al., 2007). Randonia belongs to Randoninae as characterized by

\footnotetext{
* Corresponding Author

Ahmed Elkhateeb, Department of Phytochemistry and Plant Systematics, National Research Centre, 33 El Bohouth St., Dokki, Giza, Egypt.

E mail: elkhateeb.ahmed @ gmail.com, Tel: +201116757520
}

the perigynous flowers while Oligomeris, Ochradenus and Reseda are belonging to Resedinae which has hpogynous flowers. Oligomeris linifolia (Vahl) Macbr. (Resedinae: Resedeae: Resedaceae) is one of four Oligomeris species, commonly named as lineleaf whitepuff. It is native to some parts of the Middle East India, Southern Europe, North Africa and North America. The plant grows in many habitat types including deserts, saline soils, plains, coastline, and other places. It is an annual herb, up to $50 \mathrm{~cm}$ tall, with a linear leaves and white flowers. We have previously reported the first phytochemical investigation of $O$. linifolia which leads to the isolation of eleven compounds; one sterol, five flavonols, one nucleotide, two phenolic acids and two free sugars (Hussein et al., 2013). To the best of our knowledge, except the above mentioned report, there are no reports about this plant. Therefore, more investigation was of a great importance. In the current study, for a detailed phytochemical investigation, we have used the LC-ESI-MS analysis for butanol, methanol and water fractions of $O$. linifolia and checking their cytotoxic and antioxidant activities. 


\section{EXPERIMENTAL}

\section{LC-ESI-MS analysis}

LC-ESI-MS analysis: HPLC (Waters Alliance 2695) \& MS spectrometry (Waters 3100). The mobile phase was freshly prepared by filtering through membrane disc filter $(0.45 \mu \mathrm{m})$ then degassed by sonication. For gradient elution, the mobile phase consists of solvent A $\left(0.1 \%\right.$ formic acid $(\mathrm{FA})$ in $\left.\mathrm{H}_{2} \mathrm{O}\right)$ and solvent B $\left(0.1 \%\right.$ FA in $\left.\mathrm{CH}_{3} \mathrm{CN} / \mathrm{MeOH}(1: 1 ; \mathrm{v} / \mathrm{v})\right)$. The linear gradient profile was as follows: $95 \%$ A (5 $\mathrm{min}), 95-90 \%$ A (10 min), 90$50 \%$ A (55 min), $50-95 \%$ A (65 min), and $95 \%$ A (70 min). The injection volume was $10 \mu \mathrm{L}$. The flow rate $(0.6 \mathrm{~mL} / \mathrm{min})$ was split 1:1 before the MS interface with negative ion mode parameters (source temperature $150^{\circ} \mathrm{C}$, desolvation temperature $350^{\circ} \mathrm{C}$, cone gas flow $50 \mathrm{~L} / \mathrm{h}$, cone voltage $50 \mathrm{eV}$, capillary voltage $3 \mathrm{kV}$, and desolvation gas flow $600 \mathrm{~L} / \mathrm{h}$ ). Spectra were recorded in the ESI negative mode between $50-1000 \mathrm{~m} / \mathrm{z}$. The peaks and spectra were processed using the Maslynx 4.1 software. The flavonoids isolated from O. linifolia in our previous study (Hussein et al., 2013), together with other pure flavonoids, obtained from Phytochemical and Plant Systematic Department, were used as reference samples. Known compounds were confirmed by comparing their retention times and mass spectra with standards. Unknowns were tentatively identified by comparing their mass fragmentation pattern with literatures.

\section{Plant Material}

O. linifolia was collected in March 2010 from Cairo-El Fayium desert road $(73 \mathrm{~km})$, and identified by Dr. Sameh Reda Hussein. A voucher specimen (s.n.820) was deposited in the herbarium of the National Research Center (CAIRC).

\section{Cell culture and sample treatment}

The cell line under investigation were human breast adenocarcinoma (MCF7), human hepatocellular carcinoma cell line (HEPG 2), human lung carcinoma (A549) and human colon cell line (HCT116). They were purchased from American Tissue Culture Collection. HEPG2, MCF7 and HCT116 cells lines were cultured in RPMI 1640 medium while A549 cell line was cultured in DMEM media. Media were prepared as a mixture of $1 \%$ antibiotic antimycotic $\left(10,000 \mathrm{Uml}^{-1}\right.$ potassium penicillin, 10,000 $\mu \mathrm{gml}^{-1}$ streptomycin sulphate and $25 \mu \mathrm{gm}^{-1}$ amphotericin B), $1 \%$ L-glutamine and $10 \%$ fetal bovine serum. According to the cells growth profile, cells were seeded with a density of $1 \times 10^{4}$ cell per well. This number was sufficient to give a reliable reading with the MTT assay, which corresponded well with the cell number and was the one that gave exponential growth throughout the incubation period with the tested sample (Ibrahim et al., 2013).

\section{Free radical scavenging activity (DPPH: 1,1-diphenyl -2-picryl hydrazyl)}

DPPH in methanol $(0.1 \mathrm{mM})$ solution was prepared and then $1 \mathrm{ml}$ was added to $3 \mathrm{ml}$ of the three tested extracts and standard solutions, separately. Trolox was used as reference. Four concentrations of tested samples $(50 \mu \mathrm{g} / \mathrm{ml}, 100 \mu \mathrm{g} / \mathrm{ml}, 200 \mu \mathrm{g} / \mathrm{ml}$, $300 \mu \mathrm{g} / \mathrm{ml})$ and standard $(1.0 \mu \mathrm{g} / \mathrm{ml}, 2.5 \mu \mathrm{g} / \mathrm{ml}, 5.0 \mu \mathrm{g} / \mathrm{ml})$ were prepared using methanol. Solutions were kept for $30 \mathrm{~min}$ in dark and their absorbances were measured at $517 \mathrm{~nm} .3 \mathrm{ml}$ of methanol were used as blank. The capability to scavenge the DPPH radical was calculated using the following equation: DPPH Scavenged $(\%)=\left\{\left(\mathrm{A}_{0}-\mathrm{A}_{1}\right) / \mathrm{A}_{0}\right\} \times 100$, where $\mathrm{A}_{0}$ is the absorbance of the blank and $\mathrm{A}_{1}$ is the absorbance of test sample (Sharma et al., 2004). The antioxidant activity of was expressed in $\mathrm{IC}_{50}$ values (concentration in $\mu \mathrm{g} / \mathrm{ml}$ of test sample which scavenges free radicals by $50 \%$ ).

\section{RESULTS AND DISCUSSION}

\section{Identification of phenolic compounds.}

In the present study, the LC-ESI-MS analysis was investigated for the n-butanol, methanol and water fractions of $O$. linifolia using negative ion mode technique due to its high sensitivity in the analysis of different polyphenols (Cuyckens and Claeys, 2004). Twenty-one compounds were identified; sixteen for the first time from this plant and five were previously reported (Hussein et al., 2013). The HPLC chromatograms of the different extracts are shown in Figure (1) and the tentative identification of phenolic compounds is shown in Table (1).

In this study three compounds were identified as phenolic acids, (compounds 1, 11 and 19), and eighteen compounds were identified as flavonoids. The previously isolated flavonoids were detected at peaks 6, 12, 17, 18 and 21 and confirmed by comparing their retention times and mass spectra with the authentic samples (Hussein et al., 2013). Compound 1 was tentatively identified as dihydroxybenzoyl caffeic acid which showed a pseudo-molecular ion at $\mathrm{m} / \mathrm{z}, 315$ and a fragment ion at $\mathrm{m} / z 153$ [M-(caffeic acid- $\mathrm{H}_{2} \mathrm{O}$ )-H] (Zamboni et al., 2010). The ESI-MS fragmentation pattern of compound $\mathbf{1 1}$ showed a molecular anion peak at $m / z, 341$ and three fragments at $m / z: 179$ [caffeic acid-H], 161 [caffeic acid- $\left.\mathrm{H}-\mathrm{H}_{2} \mathrm{O}\right]$, and $135[\mathrm{M}-\mathrm{H}-$ hexose- $\left.\mathrm{CO}_{2}\right]$. This suggests that compound $\mathbf{1 1}$ is caffeic acid- $O$ hexoside (Munekata et al., 2016). Compound 19 showed the same fragments of compound $\mathbf{1 1}$ in addition to a molecular ion peak at $\mathrm{m} / \mathrm{z} 683[\mathrm{M}-\mathrm{H}]^{-}$which revealed the tentative identification of compound 19 as caffeic acid-O-hexoside dimer (Chen et al., 2011). Compound 2 showed a deprotonated molecular ion $[\mathrm{M}-\mathrm{H}]$ at $m / z 609$. The predominant fragment at $m / z, 447$ is corresponding to loss of hexose [M-H-162] as ether linkage, while that at $m / z, z 57$ [M-H-hexose-90], suggested the mono- $C$-glycosylation. Therefore, compound $\mathbf{2}$ was tentatively identified as kaempferol$O$-hexoside- $C$-hexoside (Vallverdú-Queralt et al., 2011). In their ESI-MS spectra, compounds $\mathbf{3}$ and $\mathbf{1 0}$ showed the characteristic pattern of acylated flavonoid-hexoside. They showed caffeic acid peak at $\mathrm{m} / \mathrm{z}, 179$ and caffeic acid-hexoside peak at $\mathrm{m} / \mathrm{z} 341$. Compound 3 showed a deprotonated molecular ion at $m / z, 639$ and fragment ion at $\mathrm{m} / \mathrm{z} 447$ [M-H-caffeoyl]', while $\mathbf{1 0}$ showed a deprotonated molecular ion at $\mathrm{m} / \mathrm{z}, 609$ and fragment ion at $\mathrm{m} / \mathrm{z}, 477$ [M-H-caffeoyl]. Aglycones of $\mathbf{3}$ and $\mathbf{1 0}$ were suggested to be isorhamnetin $(\mathrm{m} / \mathrm{z}, 315)$ and kaempferol $(\mathrm{m} / \mathrm{z}, 285)$, respectively. 
Therefore, compounds $\mathbf{3}$ and $\mathbf{1 0}$ were tentatively identified as isorhamnetin- $O$-caffoyl hexoside and kaempferol- $O$-caffeoyl hexoside, respectively (Parejo et al., 2004). Compound 4 displayed [M-H] ion at $m / z, 595$ and showed the characteristic fragments of flavonoids-di- $C$-glycoside at $m / z$ : 505 [M-H-90]', 475 [M-H-120]', $385[272+113]^{-}$and $355[272+83]^{-}$, with 272 is corresponding to the molecular weight of naringenin leads to its identification as naringenin-6,8-di- $C$-hexoside (Llorent-Martínez et al., 2016). Compound 5 showed a deprotonated ion $[\mathrm{M}-\mathrm{H}]^{-}$at $\mathrm{m} / \mathrm{z}, 887$ which further fragmented giving three fragments at $m / z: 725$ [M-H-162], 609 [M-H-162-116], 447 [M-H-2(162)-116]. Finally, the aglycone unit was characterized as kaempferol from the fragment at $\mathrm{m} / z 285$ [M-H-3(162)-116]. The neutral loss of $278 \mathrm{Da}$ is characteristic for the loss of hexose-malic acid moiety (AbuReidah et al., 2015). Consequently, compound 5 was identified as kaempferol- $O$-trihexoside malic acid. By the same manner compound $\mathbf{8}$ was identified as kaempferol- $O$-dihexoside malic acid. Also, compound $\mathbf{9}$ is a flavonoid conjugated with glycosidemalic acid. It showed a molecular anion peak [M-H] ${ }^{-}$at $\mathrm{m} / \mathrm{z} 871$ which gave fragment at $m / z, 725$ due to loss of rhamnose unit [MH-146 ], followed by fragment at $m / z, 609$ due to loss of malic acid unit [M-H-146-116] . Finally, it gave two fragments at $m / z 447$ and 285 due to the successive loss of two hexose units leads to its tentative identification as kaempferol- $O$-dihexoside-rhamnoside malic acid.

Compound 7 was characterized as isorhamnetin 3,7-di$O$-glucopyranoside by comparing its retention time and mass spectrum with the authentic. Compound $\mathbf{1 3}$ with a molecular anion peak $[\mathrm{M}-\mathrm{H}]^{-}$at $\mathrm{m} / \mathrm{z} 609$ gave fragment at $\mathrm{m} / \mathrm{z} 447$ due to loss of hexose unit [M-H-162] and obtained another fragment at $m / z 285$ due to loss of another hexose moiety which characterized the $O$ glycosylation on phenolic hydroxyls. Based on the above mentioned data, compound $\mathbf{1 3}$ was tentatively identified askaempferol- $O$-di-hexoside. Similarly, compound $\mathbf{1 4}$ was tentatively characterized as isorhamnetin-di- $O$-hexoside. Compound 15 showed a pseudo molecular ion peak $(\mathrm{m} / \mathrm{z}, 447)$ and a fragment $(\mathrm{m} / \mathrm{z}, 285)$ due to loss of hexose unit [M-H-162] confirmed its identification as kaempferol- $O$-hexoside. By the same manner, 16 was characterized as isorhamnetin- $O$-hexoside. Compound 21 was identified as kaempferol by comparing its mass spectra with standard.

\section{Antioxidant activity and cytotoxic screening}

The results of antioxidant activity (DPPH assay) of the three fractions were recorded scavenging properties as ordered in ascending: butanol > methanol > water with $\mathrm{IC}_{50}$ values of 10.37 , 31.07 and $91.86 \mu \mathrm{g} / \mathrm{ml}$, respectively, compared with that of the standard; Trolox $(33.55 \mu \mathrm{g} / \mathrm{ml})$. The sequence of these activities could be due to the quantity of the detected compounds of the three successive fractions (Table. 1, Figure. 1).

The cytotoxic screening showed weak effect for butanol, methanol and water fractions against HCT116, A549 and MCF7 at $100 \mathrm{mg} / \mathrm{ml}$ with $(11.3,6.8,15.3) \%,(2.9,0,14.8) \%$ and $(0,5.6$, 8.3) $\%$, respectively, as well as no effect against HEPG2.

Table 1: Phenolic compounds identified from $O$. linifolia.

\begin{tabular}{|c|c|c|c|c|c|c|c|c|}
\hline Peak No. & $\begin{array}{c}\mathbf{R}_{\mathbf{t}} \\
(\mathbf{m i n})\end{array}$ & $\mathbf{M}$ & $\begin{array}{l}{[\mathbf{M}-} \\
\mathbf{H}]^{-}\end{array}$ & $m / z$ Fragments & Identification & $\begin{array}{c}\text { BuO } \\
\mathbf{H}\end{array}$ & $\begin{array}{c}\mathrm{MeO} \\
\mathrm{H}\end{array}$ & $\mathbf{H}_{2} \mathbf{O}$ \\
\hline $\mathbf{1}$ & 13.94 & 316 & 315 & $153,179,135,107$ & Dihydroxy benzoyl caffeic acid & - & - & + \\
\hline 2 & 21.79 & 610 & 609 & 447,357 & Kaempferol- $O$-hexoside- $C$-hexoside & + & + & + \\
\hline 3 & 23.04 & 640 & 639 & $477,315,179$ & Isorhamnetin- $O$ - caffoyl hexoside & + & + & - \\
\hline 4 & 25.1 & 596 & 595 & $385,355,313$ & Naringenin-6,8-di- $C$-hexoside & + & + & + \\
\hline 5 & 26.13 & 888 & 887 & $725,609,447,285$ & Kaempferol- $O$ - tri-hexoside malic acid & + & + & + \\
\hline 6 & 27.22 & 610 & 609 & 447,285 & Kaempferol 3,7-di- $O$-glucopyranoside ${ }^{\text {a }}$ & + & + & + \\
\hline 7 & 27.72 & 640 & 639 & 477,315 & Isorhamnetin 3, 7-di-O-glucopyranoside ${ }^{\text {b }}$ & + & + & + \\
\hline 8 & 31.14 & 726 & 725 & $609,447,285$ & Kaempferol-O- di-hexoside malic acid & + & - & - \\
\hline 9 & 31.31 & 872 & 871 & $\begin{array}{l}755,725,609,447 \\
285\end{array}$ & $\begin{array}{l}\text { Kaempferol-O-di-hexoside-rhamnoside malic } \\
\text { acid }\end{array}$ & + & + & + \\
\hline 10 & 32.8 & 610 & 609 & $447,285,179$ & Kaempferol - $O$ - caffoyl hexoside & + & + & + \\
\hline 11 & 33.98 & 342 & 341 & $179,161,135$ & Caffeic acid-O-hexoside ${ }^{b}$ & + & + & + \\
\hline 12 & 34.5 & 462 & 461 & 315 & Isorhamnetin $4^{\prime}-O$-rhamnopyranoside ${ }^{\text {a }}$ & + & - & - \\
\hline 13 & 36.4 & 610 & 609 & 447,285 & Kaempferol di- $O$-hexoside & - & + & - \\
\hline 14 & 36.56 & 640 & 639 & 477,315 & Isorhamnetin-di- $O$-hexoside & - & + & - \\
\hline 15 & 39.41 & 448 & 447 & 447,285 & Kaempferol - $O$-hexoside & + & + & + \\
\hline 16 & 39.6 & 478 & 477 & 315 & Isorhamnetin- $O$-hexoside & + & + & + \\
\hline 17 & 43.4 & 448 & 447 & 447,285 & Kaempferol 3-O-glucoside ${ }^{\text {a }}$ & + & + & + \\
\hline 18 & 43.7 & 478 & 477 & 315 & Isorhamnetin 3-O-glucoside ${ }^{\text {a }}$ & + & + & + \\
\hline 19 & 44.8 & 684 & 683 & $341,179,161,135$ & Caffeic acid-O-hexoside dimer & + & - & - \\
\hline 20 & 47.01 & 286 & 285 & 179,151 & Kaempferol $^{\text {b }}$ & + & - & + \\
\hline 21 & 53.8 & 316 & 315 & 179,151 & Isorhamnetin $^{\text {a }}$ & + & - & - \\
\hline
\end{tabular}

${ }^{\text {a }}$ Compound isolated previously from $O$. liniofolia, (Hussein et al., 2013), and confirmed by comparing their retention times and mass spectra with the authentic, ${ }^{b}$ Compounds identified by comparing their retention times and mass spectra with the authentic, $\mathrm{R}_{\mathrm{t}}$ Retention time. 


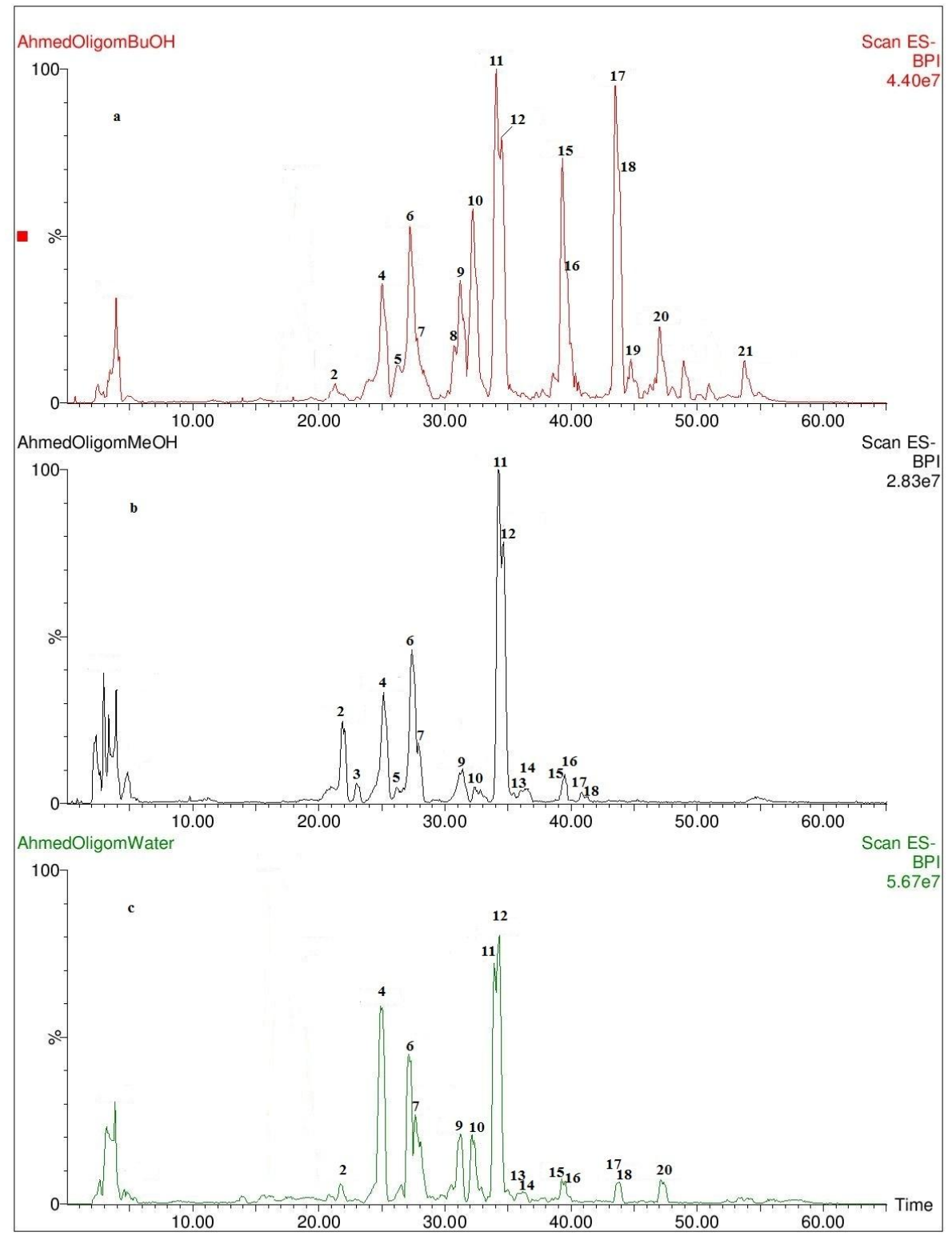

Fig. 1: LC-ESI-MS chromatogram of Oligomeris linifolia; a: n-butanol, b: methanol and c: water fractions.

\section{Chemosystematic significance}

From the chemosystematic point of view, the flavonoids detected in the present study provide additional data to further our knowledge on the infrageneric relationship of $O$. linifolia within the tribe Resedeae (family Resedaceae). Eighteen flavonoids were identified or tentatively identified from three successive fractions of $O$. linifolia; five of them were pervious reported from its aqueous methanol extract. They are belonging to flavonol $O$ glycosides (kaempferol and isorhamnetin), flavonol $C$-glycosides (kaempferol $C$-hexoside- $O$-hexoside), flavonol $O$-acyl glycosides $(O$-malic and $O$-caffeic acid hexosides of kaempferol), and dihydroflavones (naringenin $\mathrm{di}-\mathrm{C}$-hexoside). Either flavonol mono- $O$-hexoside (3 and/or 7-glucoside) or flavonol di- $O$-hexosides (3-diglucosides, 3,7-diglucosides and/or 3,4'-diglucosides ) of kaempferol and/or isorhamnetin were reported in the most species of tribe Resedeae (Berrehal et al., 2006; Makboul et al., 1989). The acylated flavonols were also reported in Ochradenus baccatus (Barakat et al., 1991), Reseda muricata and Reseda alba (El-Sayed et al., 2001) of the same sub tribe; Resedinae. Additionally, the sub tribe Randoninae (Randonia africana) still characterized by the presence of methylated flavonol glycosides (Berrehal et al., 2010; Hussein et $a l ., 2013)$. Since our previous study reported that $O$. linifolia is the only species of tribe Resedeae which characterized by its facility to produce a flavonol 4 '-mono- $O$-glycoside (Hussein et al., 2013), however the present study also supported its characterization by the ability to synthesis the $C$-hexoside derivatives of kaempferol and naringenin. 


\section{CONCLUSION}

The antioxidant and cytotoxic activities together with the LC-ESI-MS profile were investigated for the n-butanol, methanol and water fractions of $O$. linifolia. Twenty-one phenolic compounds, among them sixteen compounds were firstly reported giving more information about the phenolic content of this plant. Butanol and methanol fractions showed higher antioxidant activity than water fraction. The three fractions showed weak effect against HCT116, A549 and MCF7 and no effect against HEPG2. Our study revealed that $O$. linifolia can synthesizes flavonol $4^{\prime}$-mono$\mathrm{O}$-glycoside and the $\mathrm{C}$-hexoside derivatives of kaempferol and naringenin.

\section{Financial support and sponsorship: Nil.}

Conflict of Interests: There are no conflicts of interest.

\section{REFERENCES}

Abu-Reidah IM, Ali-Shtayeh MS, Jamous RM, Arráez-Román D, Segura-Carretero A. HPLC-DAD-ESI-MS/MS screening of bioactive components from Rhus coriaria L.(Sumac) fruits. Food Chem, 2015; 166:179-191.

Barakat HH, El-Mousallamy AM, Souleman AM, Awadalla S. Flavonoids of Ochradenus baccatus. Phytochemistry, 1991; 30:37773779 .

Berrahal D, Kabouche A, Kabouche Z, Bruneau C. Flavonoid glycosides from Reseda villosa (Resedaceae). Biochem. Syst. Ecol, 2006; 34:777-779.

Berrehal D, Khalfallah A, Kabouche A, Kabouche Z, Karioti A, Bilia AR. Flavonoid glycosides from Randonia africana Coss.(Resedaceae). Biochem. Syst. Ecol, 2010; 38:1007-1009.

Chen HJ, Inbaraj BS, Chen BH. Determination of phenolic acids and flavonoids in Taraxacum formosanum Kitam by liquid chromatography-tandem mass spectrometry coupled with a post-column derivatization technique. Int. J. Mol. Sci., 2011; 13:260-285.

Cuyckens F, Claeys M. Mass spectrometry in the structural analysis of flavonoids. J. Mass Spectrom, 2004; 39:1-15.

El-Sayed NH, Omara NM, Yousef AK, Farag AM, Mabry TJ. Kaempferol triosides from Reseda muricata. Phytochemistry, 2001; 57:575-578.

Hussein SR, Elkhateeb A, Marzouk MM, Ibrahim LF, Kawashty SA. Phytochemical investigation of Oligomeris linifolia (Vahl) Macbr.(Resedaceae). Biochem Syst Ecol, 2013; 49:73-76.
Ibrahim LF, Marzouk MM, Hussein SR, Kawashty SA, Mahmoud K, Saleh NA. Flavonoid constituents and biological screening of Astragalus bombycinus Boiss. Nat. Prod. Res., 2013; 27:386-393.

Llorent-Martínez EJ, Ortega-Barrales P, Zengin G, Uysal S, Ceylan R, Guler GO, Mocan A, Aktumsek A. Lathyrus aureus and Lathyrus pratensis: characterization of phytochemical profiles by liquid chromatography-mass spectrometry and evaluation of their enzyme inhibitory and antioxidant activities. RSC Advances, 2016; 6:88996-9006.

Makboul MA, Abdel-Baky AM, Ramadan MA. Flavonoids of Reseda pruinosa Del. growing in Egypt. Bull. Fac. Sci, 1989; 18:1-7

Martín-Bravo S, Meimberg H, Luceño M, Märkl W, Valcárcel V, Bräuchler C, Vargas P, Heubl G. Molecular systematics and biogeography of Resedaceae based on ITS and trnL-F sequences. Mol Phylogenet Evol, 2007; 3:1105-1120.

Munekata PE, Franco D, Trindade MA, Lorenzo JM. Characterization of phenolic composition in chestnut leaves and beer residue by LC-DAD-ESI-MS. LWT- Food Sci. Technol, 2016; 68:52-58.

Parejo I, Jauregui O, Viladomat F, Bastida J, Codina C. Characterization of acylated flavonoid-O-glycosides and methoxylated flavonoids from Tagetes maxima by liquid chromatography coupled to electrospray ionization tandem mass spectrometry. Rapid Commun Mass, 2004; 18:2801-2810.

Sharma A, Bhardwaj S, Mann AS, Jain A, Kharya MD. Phcog Rev.: Review Article Screening Methods of Antioxidant Activity: An Overview. Pharmacogn Rev, 2007; 1(2).

Vallverdú-Queralt A, Jáuregui O, Di Lecce G, Andrés-Lacueva C, Lamuela-Raventós RM. Screening of the polyphenol content of tomatobased products through accurate-mass spectrometry (HPLC-ESI-QTOF). Food Chem, 2011; 129:877-883.

Zamboni A, Di Carli M, Guzzo F, Stocchero M, Zenoni S, Ferrarini A, Tononi P, Toffali K, Desiderio A, Lilley KS, Pè ME Identification of putative stage-specific grapevine berry biomarkers and omics data integration into networks. Plant Physiol, 2010; 154:1439-1459.

\section{How to cite this article:}

El-Hagrassi AM, Elkhateeb A, Hussein SR, Abdel-Hameed ES, Marzouk MM. LC-ESI-MS profile, antioxidant activity and cytotoxic screening of Oligomeris linifolia (Vahl) Macbr. (Resedaceae). J App Pharm Sci, 2017; 7 (08): 043-047. 